\title{
Article
}

\section{Novel hydrogels containing Nafion and poly (ethylene oxide) based block copolymers}

Kelarakis, Antonios, Krysmann, Marta and Fernandes, Diogo Andre jardoso

Available at http://clok.uclan.ac.uk/17714/

Kelarakis, Antonios ORCID: 0000-0002-8112-5176, Krysmann, Marta ORCID: 0000-0002-8036-4925 and Fernandes, Diogo Andre jardoso (2017) Novel hydrogels containing Nafion and poly (ethylene oxide) based block copolymers. Polymer, 114 . pp. 73-78. ISSN 0032-3861

It is advisable to refer to the publisher's version if you intend to cite from the work. http://dx.doi.org/10.1016/j.polymer.2017.02.094

For more information about UCLan's research in this area go to http://www.uclan.ac.uk/researchgroups/ and search for < name of research Group>.

For information about Research generally at UCLan please go to http://www.uclan.ac.uk/research/

All outputs in CLoK are protected by Intellectual Property Rights law, including Copyright law. Copyright, IPR and Moral Rights for the works on this site are retained by the individual authors and/or other copyright owners. Terms and conditions for use of this material are defined in the policies page.

\section{CLoK}

Central Lancashire online Knowledge www.clok.uclan.ac.uk

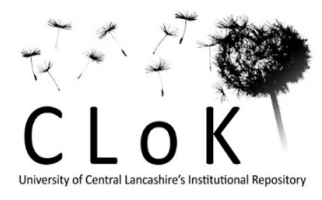




\title{
Novel hydrogels containing Nafion and poly(ethylene oxide) based block copolymers
}

D. Fernandes ${ }^{a}$, W. Kluska ${ }^{a}$, J. Stanislawska ${ }^{a}$, B. Board ${ }^{a}$, M. J. Krysmann ${ }^{b}$ and A. Kelarakis $^{a^{*}}$

${ }^{a}$ Centre for Materials Science, School of Physical Sciences and Computing, University of Central Lancashire, Preston PR12HE, U.K.

${ }^{b}$ School of Pharmacy and Biosciences, University of Central Lancashire, Preston PR12HE, U.K.

email: akelarakis@uclan.ac.uk, tel: 004417724172

\begin{abstract}
We present a novel family of biocompatible hydrogels containing Nafion and poly(ethylene oxide) based block copolymers. In aqueous environment, thermodynamically stable ionomercopolymer complexes are formed, as evident by light scattering and quartz crystal microbalance experiments. Moreover, incorporation of Nafion dramatically modifies the phase behaviour and the rheological properties of copolymer hydrogels. The hybrid systems not only undergo sharp and thermally reversible sol-gel transitions below the body temperature, thus retaining their injectable nature, but they also generate mechanically robust hydrogels. Moreover, ibuprofen was continuously released over a period of 26 days for the Nafion/Pluronic hydrogel, compared to only 3 days for the Nafion-free system. The hybrid gels are promising candidates for 3D-bioprinting and controlled drug release applications.
\end{abstract}

keywords: Nafion; Pluronics; poly(ethylene oxide); hydrogels; injectable; drug release.

\section{Introduction}

Hydrogels are water swollen networks of chemically or physically crosslinked macromolecular chains having a highly porous structure that exhibit complex viscoelastic characteristics ${ }^{1-3}$. The physical properties of those soft systems can be largely tuned with respect to the chemical composition of the polymeric components and their crosslinking density. Stimuli- responsive hydrogels can sense and adapt to changes in their surroundings such as temperature, $\mathrm{pH}$, ionic strength, pressure, light, electric field and the presence of certain chemical trigers ${ }^{4,5}$.

Particular emphasis is given to the development of injectable systems ${ }^{6,7}$ that gel in situ under physiological conditions facilitating the controlled and sustained release of the entrapped drugs. Because they 
can be applied in nonsurgical treatments (tissue engineering, drug delivery, wound repair, dermal filling, etc.), they offer obvious advantages in terms of therapy cost and duration as well as patient comfort and recovery. Injectable hydrogels are derived by natural polymers (such as hyaluronic acid ${ }^{8}$, cellulose $^{9}$, proteins and peptides ${ }^{10}$, chitosan $^{11}$ ) or synthetic macromolecules (composed of acrylates methacrylates, vinyl ethers, cyclic esters, amino acids, acrylamides, etc.) $)^{12}$.

The dynamic presence of poly(ethylene oxide) (PEO) based copolymers in the field of injectable hydrogels can be traced back to their interesting self-assembly properties that allow sharp sol-gel thermoreversible transitions below body temperature ${ }^{13,14}$. This class of nanostructured gels exhibit minimal cytotoxicity and improved pharmacokinetics ${ }^{15}$, but they typically suffer from weak mechanical properties and rapid drug release. Well-explored approaches to overcome those challenges rely on the development of photocrosslinked ${ }^{16}$, stereocomplexed ${ }^{17}$ and multicomponent ${ }^{18}$ systems.

In this report we demonstrate that introduction of Nafion to hydrogels containing PEO based copolymers improves their drug release profile and enhances their mechanical strength, without compromising their injectable character. Nafion is primarily known as the proton exchange membrane in fuel cells ${ }^{19,20}$. Early studies have demonstrated its biocompatible nature ${ }^{21,22}$, but it has only recently attracted significant attention for biomedical applications such as implant coatings ${ }^{23}$, biosensors $^{24,25}$ and biocompatible capsules ${ }^{26}$. Its amphiphilic structure consists of a remarkably robust Teflon-like backbone decorated with highly polar pendant groups. Due to this macromolecular design, Nafion interacts strongly with non-ionic block copolymers 27,28 giving rise to thermodynamically stable supramolecular assemblies.

\section{Experimental Section}

\subsection{Materials}

Two Nafion dispersions (in water and low aliphatic alcohols, respectively) were obtained by Ion Power. Pluronic P123 was obtained by Sigma Aldrich and is referred here as $\mathrm{E}_{19} \mathrm{P}_{69} \mathrm{E}_{19}$. The notations are as follows: $\mathrm{E}$ stands for an oxyethylene unit $\mathrm{OCH}_{2} \mathrm{CH}_{2}$, $\mathrm{P}$ for oxypropylene $\mathrm{OCH}_{2} \mathrm{CH}\left(\mathrm{CH}_{3}\right)$, while the subscripts denote number-average block of repeat units. The copolymer $\mathrm{B}_{20} \mathrm{E}_{510}$, where $\mathrm{B}$ stands for an oxybutylene unit $\mathrm{OCH}_{2} \mathrm{CH}\left(\mathrm{C}_{2} \mathrm{H}_{5}\right)$, was synthesized by sequential anionic polymerization of 1,2-butylene oxide followed by ethylene oxide, using potassium activated 2-butanol as initiator ${ }^{29}$.

\subsection{Methods}

\subsubsection{Dynamic Light Scattering (DLS). DLS} measurements at $\mathrm{T}=25{ }^{\circ} \mathrm{C}$ were conducted using a Malvern Zetasizer Nano-ZS (Malvern Instruments, England) system equipped with a He-Ne laser beam with $\lambda=$ $633 \mathrm{~nm}$. Prior to the measurements the samples were filtered through Nylon membrane filters with a pore size of $0.2 \mu \mathrm{m}$ directly to the measuring cuvettes.

2.2.2. Quartz Crystal Microbalance with dissipation monitoring (QCM-D). QCM-D experiments were conducted at $\mathrm{T}=25{ }^{\circ} \mathrm{C}$ using a Q-sense E1 unit. $\mathrm{SiO}_{2}$ modified crystals with fundamental resonance frequency close to $5 \mathrm{MHz}$ were coated with 
Nafion. To that end, a drop of ethanol containing $0.5 \mathrm{wt} \%$ Nafion was deposited in each crystal that was subsequently left for at least $48 \mathrm{~h}$ at room temperature to ensure complete evaporation of the solvent. The thus prepared Nafion-coated crystals were mounted to a flow cell (flow rate $=0.2$ $\mathrm{ml} / \mathrm{min}$ ) and their interaction with water and copolymer solutions were monitored. When a layer of material with mass $\Delta m$ is deposited on the crystal surface, its resonant frequency is reduced by $\Delta f$ according to Sauerbrey relation ${ }^{30}$

$$
\Delta m=-(\mathrm{C} / \mathrm{N}) \Delta f
$$

where $\mathrm{N}$ denotes the overtone number and $\mathrm{C}$ the integrated crystal sensitivity. The dissipation factor $\mathrm{D}$ is defined as

$$
D=E_{d} /\left(2 \pi E_{s}\right)
$$

where $E_{d}$ is the energy dissipated during one period of oscillation and $E_{s}$ is the energy stored in the system ${ }^{31}$. For simplicity, only the third overtones $(\mathrm{N}=3)$ are described in this report.

\subsubsection{Rheology. The viscoelastic properties} of the hydrogels were studied using a stress controlled AR-G2 rheometer (TA). All measurements were performed within the linear viscoelastic region (strain $2 \%$ ), using a parallel plate cell with $50 \mathrm{~mm}$ diameter. Frequency sweep data were collected at selected temperatures, while temperature ramps were performed at $\omega=1 \mathrm{rad} / \mathrm{sec}$ with a heating rate of $1{ }^{\circ} \mathrm{C} / \mathrm{min}$. Extra care was taken to minimize evaporation by using a solvent trap to maintain a water saturated environment.

\subsubsection{Small Angle X-ray Scattering (SAXS).} SAXS experiments were performed on beamline I22, Diamond Light Source Synchrotron Radiation Source, U.K. The wavelength of synchrotron radiation was $1 \AA$ and the sample-to-detector distance was $6 \mathrm{~m}$. Samples were mounted between mica windows in a liquid cell equipped with water-bath temperature control. Two dimensional SAXS patterns were collected using a Pilatus P3-2M area detector. All patterns were corrected for the incident beam fluctuations as well as air and instrument scattering, before being converted into 1D profiles using the Dawn software.

2.2.5. Drug release profiles. A gel containing $32.5 \mathrm{wt} \% \mathrm{E}_{19} \mathrm{P}_{69} \mathrm{E}_{19}$ and $0.5 \mathrm{wt} \%$ ibuprofen (Sigma- Aldrich) was transferred into a Snakeskin dialysis membrane (with molecular weight cut-off $3.5 \mathrm{kDa}$ ) and was subsequently immersed in phosphate buffer saline solution $(\mathrm{pH} 7.4)$ at a constant temperature of $37^{\circ} \mathrm{C}$. Samples of the buffer solution were withdrawn at predetermined times and the ibuprofen content was determined on a basis of a calibration curve using a Shimadzu UV3600 UV-Vis, at 265 $\mathrm{nm}$. An, otherwise identical, experiment was conducted for the gel containing $32.5 \mathrm{wt} \%$ $\mathrm{E}_{19} \mathrm{P}_{69} \mathrm{E}_{19}$ and $10 \mathrm{wt} \%$ Nafion.

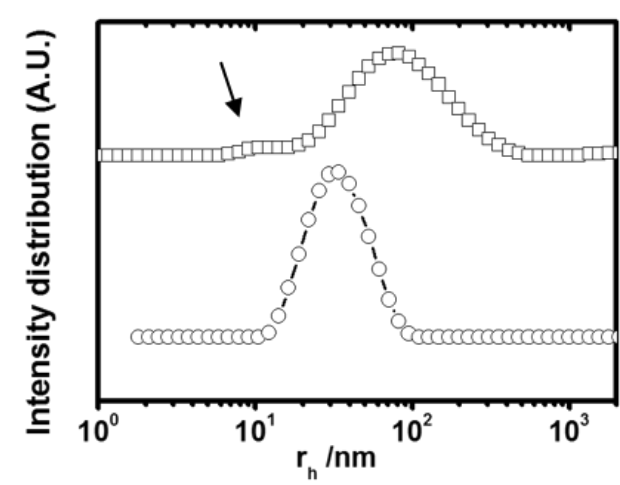

Figure 1 - Intensity fraction distributions of apparent hydrodynamic radius $\left(\mathrm{r}_{\mathrm{h}}\right)$ at $\mathrm{T}=25^{\circ} \mathrm{C}$ for aqueous solutions of $0.5 \mathrm{wt} \% \mathrm{~B}_{20} \mathrm{E}_{510}$ in the absence (circles) and in the presence (squares) of $0.5 \mathrm{wt} \%$ Nafion. For clarity, the curves are displayed in the ordinate. 


\section{Results and discussion}

Intensity fraction distributions of apparent hydrodynamic radius $\left(r_{\mathrm{h}}\right)$ of $0.5 \mathrm{wt} \%$ $\mathrm{B}_{20} \mathrm{E}_{510}$ aqueous solutions (circles in Figure 1) indicate the presence of highly swollen micelles with $\mathrm{rh}=31 \mathrm{~nm}$, in agreement with previous studies ${ }^{29}$. Judging by its B block length ${ }^{14}$, the critical micelle concentration (cmc) of $\mathrm{B}_{20} \mathrm{E}_{510}$ is expected to fall below $10^{-4} \mathrm{wt} \%$, consistent with the absence of a unimer peak. Addition of 0.5 wt\% Nafion results in particles with $\mathrm{r}_{\mathrm{h}}=80 \mathrm{~nm}$ (squares in Figure 1), an effect that suggests extensive Nafion-copolymer binding. For reference, a $0.5 \mathrm{wt} \%$ aqueous dispersion of Nafion shows a wide size distribution below $20 \mathrm{~nm}$ (data not shown here) and unbound Nafion particles might count for the minor peak observed in Figure 1.

Previous reports ${ }^{27,28}$ provide clear evidence that Nafion forms supramolecular assemblies with $\mathrm{E}_{18} \mathrm{~B}_{10}, \mathrm{E}_{19} \mathrm{P}_{69} \mathrm{E}_{19}$ and $\mathrm{M}_{18} \mathrm{E}_{20}\left(\mathrm{M}_{18}\right.$ stands for $\mathrm{C}_{18} \mathrm{H}_{37}$ ) in water. For example, the critical micelle temperature $(\mathrm{cmt})$ of $\mathrm{E}_{19} \mathrm{P}_{69} \mathrm{E}_{19}$ solutions was found to systematically increase in the presence of Nafion, indicating strong copolymer adsorption to the ionomer backbone ${ }^{27}$. The complexation has been attributed to hydrophobic interactions and extensive hydrogen bonding between Nafion's protons and the ether oxygen of $\mathrm{EO}^{32}$. It is interesting to note the architectural similarity between the copolymer's hydrophilic building block $\mathrm{OCH}_{2} \mathrm{CH}_{2-}$ and Nafion's side chain $\mathrm{OCF}_{2} \mathrm{CF}_{2}-$.

Each one of the QCM-D sensorgrams in Figure 2 describes an initial equilibrium of a Nafion coated crystal against air in order to determine the fundamental resonance frequency, followed by a subsequent equilibrium against flowing water to
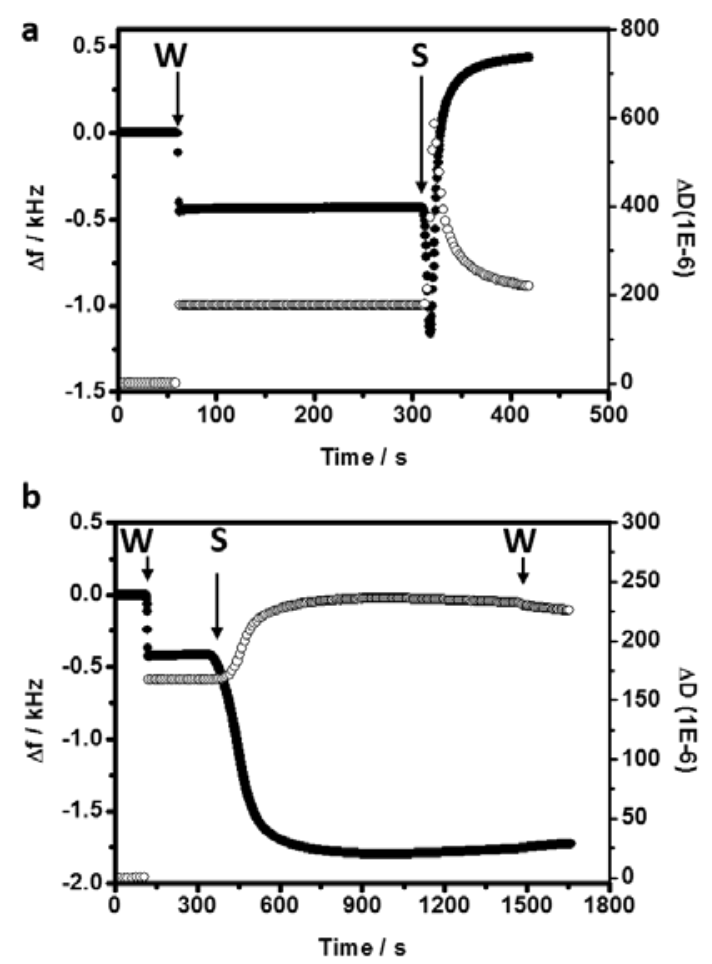

Figure 1 - Time course of frequency (filled symbols) and dissipation factor (open symbols) of a Nafion-coated crystal resonator in QCM-D experiments at $25{ }^{\circ} \mathrm{C}$. "W" and " $\mathrm{S}$ " denote the injection of water and the copolymer solutions containing $0.5 w t \% \mathrm{E}_{19} \mathrm{P}_{69} \mathrm{E}_{19}$ (a) and $0.5 \mathrm{wt} \%$ $\mathrm{B}_{20} \mathrm{E}_{510}(\mathrm{~b})$, respectively.

determine the baseline of the hydrated membrane. The pronounced drop in $f$ that follows the hydration of the crystals reveals the ample water uptake of the Nafion's ionic domains that does not, however, result in the dissolution of the membrane.

Introduction of $0.5 \mathrm{wt} \% \mathrm{E}_{19} \mathrm{P}_{69} \mathrm{E}_{19}$ solution (Figure 2a) to the hydrated Nafion membrane initially causes a dramatic decrease in $\mathrm{f}$ due to extensive copolymer adsorption, an effect that reduces the rigidity of the membrane as revealed by the accompanying increase in $\mathrm{D}$. When the amount of the attached polymer exceeds a critical threshold, a rapid increase in $\mathrm{f}$ is observed due to the dissolution of the Nafion membrane. The detergency efficiency of $\mathrm{E}_{19} \mathrm{P}_{69} \mathrm{E}_{19}$ against Nafion ultrathin membranes has been described in detail 
previously $^{27,28}$, and the underlying mechanism holds true for $\mathrm{E}_{18} \mathrm{~B}_{10}$ and $\mathrm{M}_{18} \mathrm{E}_{20}$.

Introduction of $\mathrm{B}_{20} \mathrm{E}_{510}$ solution (Figure $2 \mathrm{~b}$ ) also gives rise to a significant decrease in $\mathrm{f}$ and an accompanying increase in D, indicating rapid and extensive Nafioncopolymer binding. By virtue of their superswollen nature $(\mathrm{r}=31 \mathrm{~nm})$, the adsorbed copolymer chains impose significant steric constrains so that the rather limited amount of copolymer attached is incapable in solubilising Nafion. It has been estimated that each E-unit in the corona of $\mathrm{B}_{20} \mathrm{E}_{510}$ micelles is associated with 96 water molecules ${ }^{33}$, out of which only 6 water molecules are present in the hydration layer ${ }^{34}$ and the remaining is essentially bulk water. Nevertheless, QCM-D sensorgram suggest that $\mathrm{B}_{20} \mathrm{E}_{510}$ chains are firmly adsorbed to Nafion's surface and are not detached upon prolonged water rinsing. In contrast, in an otherwise identical experiment, it was found that a significant portion of the attached PEO on the Nafion membrane can be removed under water flow ${ }^{27}$. The difference between the two systems, highlight the role of hydrophobic-hydrophobic interactions between the substrate and the adsorbed $\mathrm{B}_{20} \mathrm{E}_{510}$ chains that are not present in the case of PEO (that lacks hydrophobic groups).

The sol-gel phase diagram of concentrated aqueous dispersions of PEO based block copolymers is governed by the exothermic dissolution of ethylene glycol that favours micellization and, thereby, micellar packing at intermediate temperatures, but also accounts for pronounced corona dehydration and collapse of the close packing at elevated temperatures. As shown in Figure 3, upon heating the $32.5 \mathrm{wt} \% \mathrm{E}_{19} \mathrm{P}_{69} \mathrm{E}_{19}$ aqueous dispersion exhibits a sharp sol- gel transition at $19{ }^{\circ} \mathrm{C}$ ( $\mathrm{G}^{\prime}$ exceeds $1 \mathrm{kPa}$ and $\left.\mathrm{G}^{\prime}>\mathrm{G}^{\prime \prime}\right)$ and the structure collapses at $42{ }^{\circ} \mathrm{C}$ into a soft gel phase ( $G^{\prime}$ falls much below $1 \mathrm{kPa}$, but remains higher than G"). Soft gels are described as defected closely packed systems, where interacting micellar aggregates give rise to a moderate viscoelastic response (e.g. stronger than sol, but weaker than a hard gel $)^{35}$.

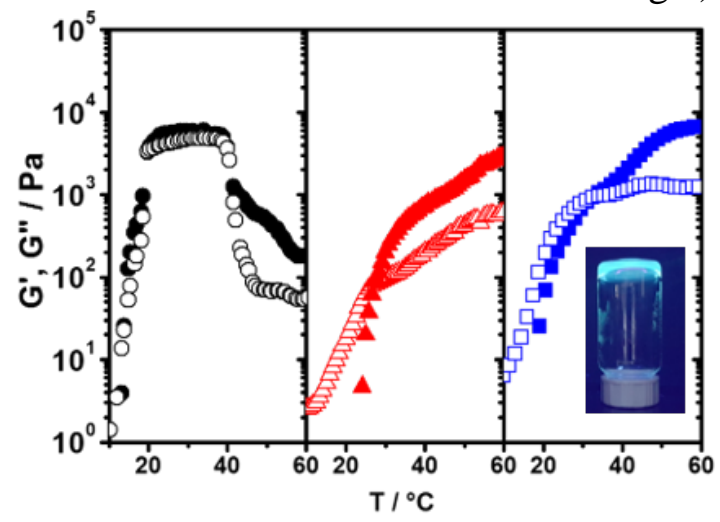

Figure 3 - Temperature sweeps $(\omega=1 \mathrm{rad} / \mathrm{s}$, strain amplitude $=2 \%$ ) for aqueous gels containing 32.5 wt $\%$ $E_{19} P_{69} E_{19}$ in the absence (black circles) and the presence of $5 \mathrm{wt} \%$ Nafion (red triangles) and $10 \mathrm{wt} \%$ Nafion (blue squares). Solid symbols denote storage modulus ( $\left.G^{\prime}\right)$ and open symbols denote loss modulus ( $\left.\mathrm{G}^{\prime \prime}\right)$. The inset shows a photo of the gel containing $32.5 \mathrm{wt} \% \mathrm{E}_{19} \mathrm{P}_{69} \mathrm{E}_{19} / 10 \mathrm{wt} \%$ Nafion at $40^{\circ} \mathrm{C}$ (a florescence dye has been added to facilitate imaging under UV radiation).

Addition of $5 \mathrm{wt} \%$ and $10 \mathrm{wt} \%$ Nafion modifies the phase diagram, given that the hybrid systems remain within the sol phase at temperatures up to 45 and $34{ }^{\circ} \mathrm{C}$ ( $\mathrm{G}^{\prime}$ exceeds $1 \mathrm{kPa}$ and $\left.\mathrm{G}^{\prime}>\mathrm{G}^{\prime \prime}\right)$, respectively and the gels formed are stable up to the highest temperature tested $\left(60{ }^{\circ} \mathrm{C}\right)$. The inset shown in Figure 3 demonstrates a tube inversion test and shows the immobile nature of a 32.5 wt\% E ${ }_{19} \mathrm{P}_{69} \mathrm{E}_{19} / 10 \mathrm{wt} \%$ Nafion gel at $40{ }^{\circ} \mathrm{C}$. Significantly, the sol-gel transitions observed for the hybrid systems are thermoreversible and they remain unaltered upon repetitive heat-cool-heat cycles. In other words, while Pluronic hydrogels tend to exhibit a sol-gelsol transition upon heating, addition of Nafion leads to a monotonous enhancement of viscoelasticity as a function of temperature. For reference, we note that a $13.9 \mathrm{wt} \%$ aqueous dispersion of the thermo and $\mathrm{pH}$ responsive linear triblock copolymer, poly(methoxydi(ethylene glycol) methacrylate-co-methacrylic acid)-b-PEO-b poly(methoxydi(ethylene glycol) methacrylate-co-methacrylic acid) at $\mathrm{pH}=4$ undergoes sol-gel transition at $36.1{ }^{\circ} \mathrm{C}$ and 
maintains a plateau $\mathrm{G}^{\prime}$ value close to $3 \mathrm{kPa}$ at least up to $65^{\circ} \mathrm{C}^{36}$.
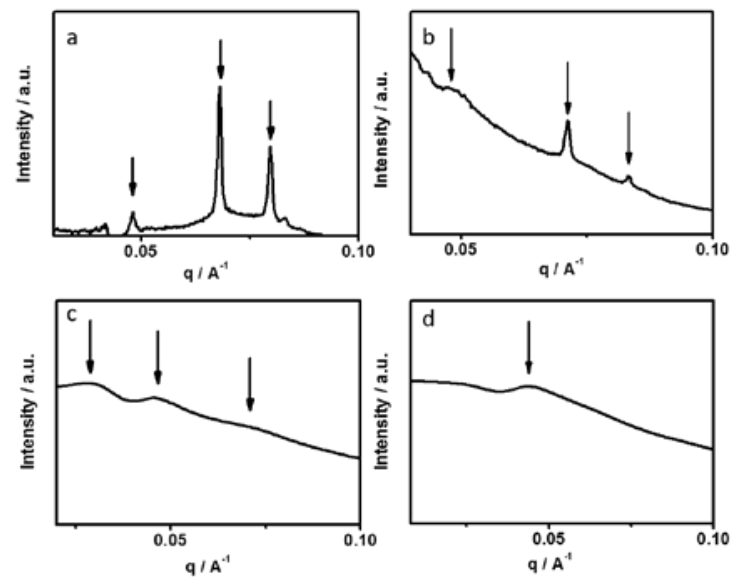

Figure 4 - SAXS patterns of aqueous gels of 32.5 wt\% $\mathrm{E}_{19} \mathrm{P}_{69} \mathrm{E}_{19}$ in the absence of Nafion (a) and in the presence of 1 wt\% Nafion (b), 5 wt\% Nafion (c) and 10 wt\% Nafion (d).

The SAXS patterns shown in Figure 4 indicate a body centered cubic (bcc) packing for $32.5 \mathrm{wt} \% \mathrm{E}_{19} \mathrm{P}_{69} \mathrm{E}_{19}$ at $20{ }^{\circ} \mathrm{C}$ with reflections at $\mathrm{q} / \mathrm{q}^{*}=1: \sqrt{2}: \sqrt{3}$, where $\mathrm{q}$ stands for the scattering vector and $q^{*}$ for the first order reflection ${ }^{37}$. The bcc structure is somewhat maintained in the presence of $1 w t \%$ Nafion, although the hybrid is a weaker gel. Addition of $5 \mathrm{wt} \%$ Nafion has a profound impact, leading to a fluid system with broad scattering peaks ( $\left.\mathrm{q} / \mathrm{q}^{*}=1: \sqrt{3}: \sqrt{7}\right)$ that are roughly consistent with hexagonal packing of cylinders ${ }^{38}$. Moreover, in the presence of $10 \mathrm{wt} \%$ Nafion the fluid system does not possess any long range correlation. The dramatic effects induced by Nafion to the phase behaviour of the gels are in line with the extensive adsorption of $\mathrm{E}_{19} \mathrm{P}_{69} \mathrm{E}_{19}$ to Nafion backbone, an effect that reduces the effective volume fraction of the dispersed particles, ultimately removing the close packing constrains. We note that SAXS profiles at $45{ }^{\circ} \mathrm{C}$ and $65{ }^{\circ} \mathrm{C}$ indicated the absence of an ordered structure for all hydrogels in the absence and in the presence of 5 and $10 \mathrm{wt} \%$ Nafion.

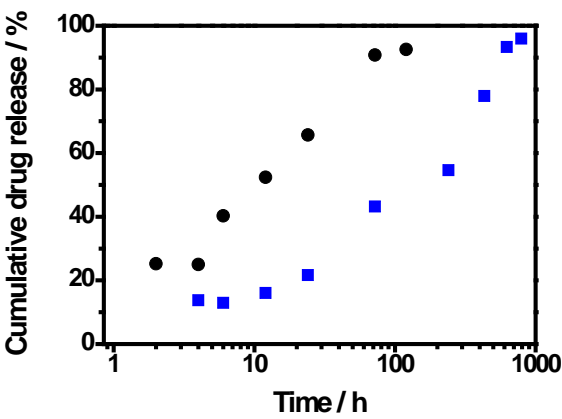

Figure 5 - Release profiles of ibuprofen from 32.5wt\% $\mathrm{E}_{19} \mathrm{P}_{69} \mathrm{E}_{19}$ in the absence (black circles) and presence (blue squares) of $10 \mathrm{wt} \%$ Nafion against phosphate buffer solution $(\mathrm{pH}=7.4)$ at $37^{\circ} \mathrm{C}$.

Figure 5 shows the release profiles of ibuprofen from $32.5 \mathrm{wt} \% \mathrm{E}_{19} \mathrm{P}_{69} \mathrm{E}_{19}$ in the absence (black circles) and presence (blue squares) of $10 \mathrm{wt} \%$ Nafion against phosphate buffer ( $\mathrm{pH}=7.4)$ solution at $37{ }^{\circ} \mathrm{C}$. A rather rapid release is observed from the copolymer gel given that 65 and $91 \mathrm{wt} \%$ of the drug was released within the first 24 and $72 \mathrm{~h}$, respectively. For reference we note, that aceclofenac and paclitaxel are fully released within $24 \mathrm{~h}$ from a Pluronic micellar solution $^{39}$ and a Pluronic hydrogel ${ }^{40}$, respectively. However, the diffusion of ibuprofen from the hybrid hydrogel is much slower given that 21, 55 and $93 \mathrm{wt} \%$ of the drug is released after 24, 240 and $624 \mathrm{~h}$, respectively. Taking into account that the two systems have similar rheological properties at $37{ }^{\circ} \mathrm{C}$ (Figure 3), the improved release profile seen for the hybrid system can be attributed to a lower level of porosity/ higher tortuosity or stronger matrix-drug interactions in the presence of Nafion. Further work is underway to elucidate the diffusion mechanism in this complex system. In a control experiment we investigated the drug release profile from an acidified 32.5 wt\% Pluronic gel $(\mathrm{pH}=3$, in accordance to that measured for the Nafion/Pluronic gel), but the effect of $\mathrm{pH}$ adjustment was found to be minimal. 

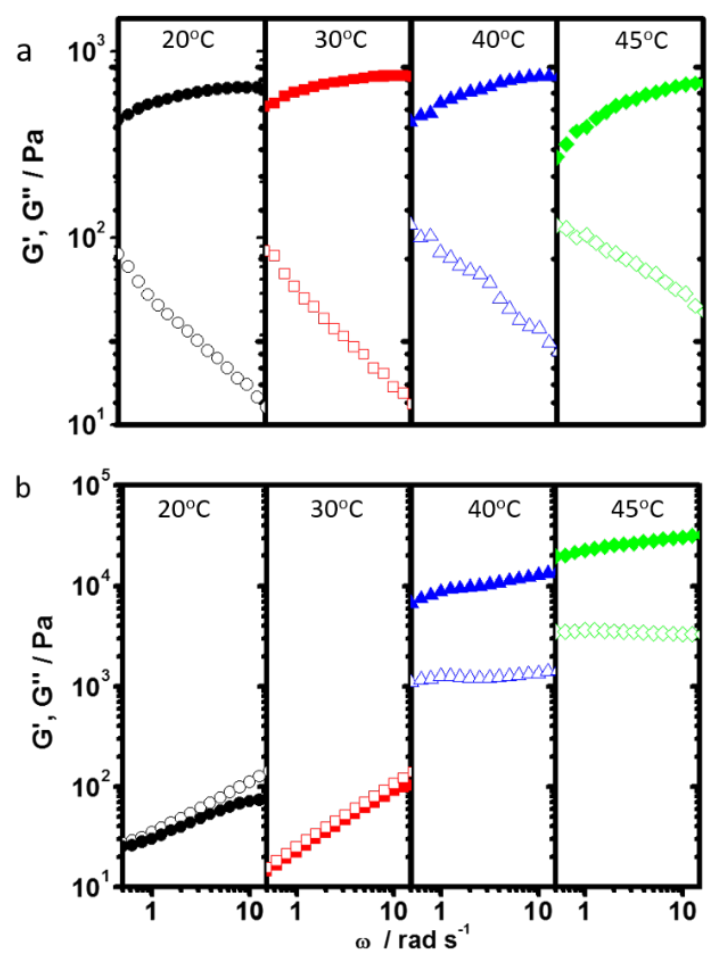

Figure 6 - Frequency dependence (strain amplitude $=2 \%$ ) of storage modulus $\left(G^{\prime}\right.$, solid symbols) and loss modulus ( $\mathrm{G}^{\prime \prime}$, open symbols) at various temperatures (black circles for $20^{\circ} \mathrm{C}$, red squares for $30{ }^{\circ} \mathrm{C}$, blue triangles for $40{ }^{\circ} \mathrm{C}$, green diamonds for 45 ${ }^{\circ} \mathrm{C}$ ) for aqueous gels containing $5 \mathrm{wt} \% \mathrm{~B}_{20} \mathrm{E}_{510}$ in the absence (a) and in the presence of 10 wt $\%$ Nafion (b).

Frequency sweeps shown in Figure 6a suggest that the $5 \mathrm{wt} \%$ aqueous solution of $\mathrm{B}_{20} \mathrm{E}_{510}$ forms a gel from 20 to $45{ }^{\circ} \mathrm{C}$ and the $\mathrm{G}^{\prime}$ show a maximum value of $800 \mathrm{~Pa}(\omega=1$ $\mathrm{rad} / \mathrm{s}$ ) at $30{ }^{\circ} \mathrm{C}$. Low $\mathrm{G}^{\prime}$ values in, otherwise immobile, gels close to their critical gel

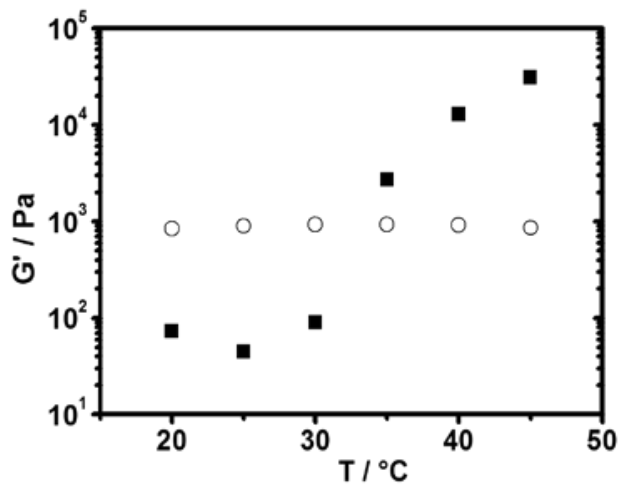

Figure 7 - Temperature dependence of storage modulus $\mathrm{G}^{\prime}(\omega=1 \mathrm{rad} / \mathrm{s}$, strain amplitude=2\%) for aqueous gels containing 5 wt $\% B_{20} \mathrm{E}_{510}$ in the absence (open circles) and in the presence of $10 \mathrm{wt} \%$ Nafion (solid squares). The data were read off from frequency sweeps measurements. concentration, have been reported previously for copolymers with long $\mathrm{E}$ blocks ${ }^{29}$. As seen in Figure 6b, introduction of $10 \mathrm{wt} \%$ Nafion allows the formation of mechanically robust hydrogels with $\mathrm{G}^{\prime}$ higher than $9 \mathrm{kPa}$ and 23 $\mathrm{kPa}(\omega=1 \mathrm{rad} / \mathrm{s})$ at $\mathrm{T}=40^{\circ} \mathrm{C}$ and $45^{\circ} \mathrm{C}$. At 40 ${ }^{\circ} \mathrm{C}$ and $45{ }^{\circ} \mathrm{C}, \mathrm{G}^{\prime}$ and $\mathrm{G}^{\prime}$ are only weakly dependent on frequency, indicating solid-like rheological response.

Figure 7 compares the temperature dependence of $\mathrm{G}^{\prime}$ for $5 \mathrm{wt} \% \mathrm{~B}_{20} \mathrm{E}_{510}$ (open circles) and $5 \mathrm{wt} \% \mathrm{~B}_{20} \mathrm{E}_{510} / 10 \mathrm{wt} \%$ Nafion (full squares) (the data points at $\omega=1 \mathrm{rad} / \mathrm{s}$ were read off from frequency sweeps and were combined in a single curve). It can be seen that within the temperature range 20 to $30{ }^{\circ} \mathrm{C}$, the hybrid gel shows one order of magnitude lower G' compared to its Nafionfree counterpart, an obvious advantage for injectable applications. At temperature above $30{ }^{\circ} \mathrm{C}$ the hybrid undergoes an abrupt (albeit thermally reversible) sol-gel transition that results in the formation of a mechanically robust hydrogel. (Due to the pronounced differences in their viscoelastic properties at $37{ }^{\circ} \mathrm{C}$ between the two systems shown in Figure 7 , we did not conduct drug release studies). Despite this abrupt phase transformation upon heating, SAXS patterns shown in Figure 8 indicate that the structure of the system lacks long range order at $15{ }^{\circ} \mathrm{C}$ as expected for a fluid, but this observation remains unaltered at $45{ }^{\circ} \mathrm{C}$, even though the hydrogel behaves rheologically as a solidlike material. With respect to the $5 \mathrm{wt} \%$ $\mathrm{B}_{20} \mathrm{E}_{510}$, we note that the bcc structure of this type of super-swollen gels close to their critical gel concentration has been confirmed so far only by SANS measurements ${ }^{41}$, while our SAXS data did not show any refractive peaks. 

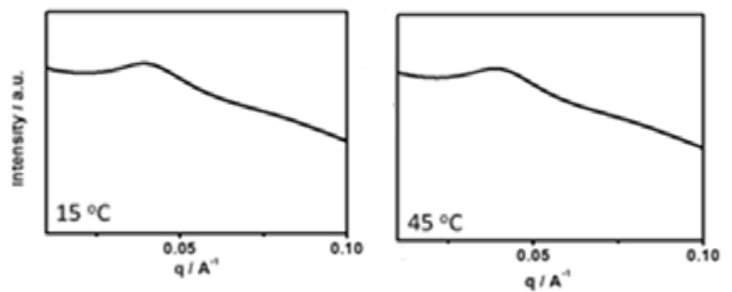

Figure 8 - SAXS patterns of an aqueous gel containing 5 wt $\% B_{20} E_{510}$ in the presence of 10 wt\% Nafion at the temperatures indicated.

\section{Conclusions}

In water, Nafion and PEO based copolymers undergo synergistic mixing as evident by light scattering and QCM-D experiments. At higher concentrations the supramolecular assemblies exhibit an abrupt sol-gel transition below body temperature, generating thermoreversibe hydrogels. The 5 wt $\% \quad \mathrm{~B}_{20} \mathrm{E}_{510} / 10 \quad$ wt $\%$ Nafion hybrid hydrogel at body temperature exhibits significantly improved mechanical strength compared to its Nafion-free counterpart. Moreover, the hybrid $\mathrm{E}_{19} \mathrm{P}_{69} \mathrm{E}_{19} / \mathrm{Nafion}$ gel exhibits dramatically improved drug release profile in vitro over a prolonged period of time. Those biocompatible systems offer exciting opportunities for the development of a new generation of super-tough nanogels and bioinks.

\section{Acknowledgements}

We thank Diamond Light Source for access to beamline I22 (SM 10168) that contributed to the results presented here. In particular, we wish to thank Dr Nick Terrill and Dr Olga Shebanova for their constant support during our visit to synchrotron facilities. W. K. and J.S. (from Adam Mickiewicz University in Poznan, Poland) were sponsored by the Erasmus mobility program to work in U.K.

\section{References}

[1] A.S. Hoffman, Stimuli-responsive polymers: Biomedical applications and challenges for clinical translation, Adv. Drug Deliv. Rev. 65 (2013) 10-16. doi:10.1016/j.addr.2012.11.004.

[2] T.R. Hoare, D.S. Kohane, Hydrogels in drug delivery: Progress and challenges, Polymer (Guildf). 49 (2008) 1993-2007. doi:10.1016/j.polymer.2008.01.027.

[3] J. Kopecek, Hydrogel biomaterials: A smart future?, Biomaterials. 28 (2007) 5185-92. doi:10.1016/j.biomaterials.2007.07.044.

[4] M.C. Koetting, J.T. Peters, S.D. Steichen, N.A. Peppas, Stimulus-responsive hydrogels: Theory, modern advances, and applications, Mater. Sci. Eng. R Reports. 93 (2015) 1-49. doi:10.1016/j.mser.2015.04.001.

[5] C. Tsitsilianis, Responsive Reversible Hydrogels from associative "smart" macromolecules, Soft Matter. 6 (2010) 2372-88. doi:10.1039/b923947b.

[6] K.H. Bae, L.-S. Wang, M. Kurisawa, Injectable biodegradable hydrogels: Progress and challenges, J. $\begin{array}{lllll}\text { Mater. } & \text { Chem. } & \text { B. } & 1 & \text { (2013) 5371-88. }\end{array}$ doi:10.1039/c3tb20940g.

[7] L. Yu, J. Ding, Injectable hydrogels as unique biomedical materials., Chem. Soc. Rev. 37 (2008) 1473-81. doi:10.1039/b713009k.

[8] X. Xu, A.K. Jha, D.A. Harrington, M.C. FarachCarson, X. Jia, Hyaluronic Acid-Based Hydrogels: from a Natural Polysaccharide to Complex Networks, Soft Matter. 8 (2012) 3280-94. doi:10.1039/C2SM06463D.

[9] C. Vinatier, O. Gauthier, A. Fatimi, C. Merceron, M. Masson, A. Moreau, F. Moreau, B. Fellah, P. Weiss, J. Guicheux, An injectable cellulose-based hydrogel for the transfer of autologous nasal chondrocytes in articular cartilage defects, Biotechnol. Bioeng. 102 (2009) 1259-67. doi:10.1002/bit.22137.

[10] A.M. Jonker, D.W.P.M. Löwik, J.C.M. Van Hest, Peptide- and protein-based hydrogels, Chem. Mater. 24 (2012) 759-73. doi:10.1021/cm202640w.

[11] H. Tan, C.M. Ramirez, N. Miljkovic, H. Li, J.P. Rubin, K.G. Marra, Thermosensitive injectable hyaluronic 
acid hydrogel for adipose tissue engineering, Biomaterials. 30

(2009)

doi:10.1016/j.biomaterials.2009.08.058.

[12] A.P. Constantinou, T.K. Georgiou, Tuning the gelation of thermoresponsive gels, Eur. Polym. J. 78 (2016) 366-75. doi:10.1016/j.eurpolymj.2016.02.014.

[13] P. Alexandridis, J.F. Holzwarth, T.A. Hatton, Micellization of Poly(ethylene oxide)-Poly(propylene oxide)-Poly(ethylene oxide) Triblock Copolymers in Aqueous Solutions: Thermodynamics of Copolymer Association., Macromolecules. 27 (1994) 2414-2425. doi:10.1021/ma00087a009.

[14] C. Booth, D. Attwood, Effects of block architecture and composition on the association properties of poly(oxyalkylene) copolymers in aqueous solution, Macromol. Rapid Commun. 21 (2000) 501-27. doi:10.1002/1521-3927(20000601)21:9<501::AIDMARC501>3.0.CO;2-R.

[15] L. Yu, J. Ding, Injectable hydrogels as unique biomedical materials., Chem. Soc. Rev. 37 (2008) 1473-81. doi:10.1039/b713009k

[16] N.E. Fedorovich, I. Swennen, J. Girones, L. Moroni, C.A. Van Blitterswijk, E. Schacht, J. Alblas, W.J.A. Dhert, Evaluation of photocrosslinked lutrol hydrogel for tissue printing applications, Biomacromolecules. 10 (2009) 1689-96. doi:10.1021/bm801463q.

[17] H.J. Chung, Y. Lee, T.G. Park, Thermo-sensitive and biodegradable hydrogels based on stereocomplexed Pluronic multi-block copolymers for controlled protein delivery, J. Control. Release. 127 (2008) 22-30. doi:10.1016/j.jconrel.2007.12.008.

[18] Y. Lee, H.J. Chung, S. Yeo, C.-H. Ahn, H. Lee, P.B. Messersmith, T.G. Park, Thermo-sensitive, injectable, and tissue adhesive sol-gel transition hyaluronic acid - pluronic composite hydrogels prepared from bio-inspired catecholthiol reaction, Soft Matter. $6 \quad$ (2010) 977. doi:10.1039/b919944f.
[19] K.A. Mauritz, R.B. Moore, State of understanding of Nafion, Chem. Rev. 104 (2004) 4535-85. doi:10.1021/cr0207123.

[20] A. Kelarakis, R.H. Alonso, H. Lian, E. Burgaz, L. Estevez, E.P. Giannelis, Nanohybrid nafion membranes for fuel cells, ACS Symp. Ser. 1034 (2010). doi:10.1021/bk2010-1034.ch012.

[21] R.F.B. Turner, D.J. Hamisont, R. V Rajotte, Preliminary in vivo biocompatibility studies on perfluorosulphonic acid polymer membranes for biosensor applications, Biomaterials. 12 (1991) 361-68. doi:10.1016/0142-9612(91)90003-S.

[22] R.F.B. Turner, C.S. Sherwood, Biocompatibility of Perfluorosulfonic Acid Polymer Membranes for Biosensor Applications, Diagnostic Biosens. Polym. 17 (1994) 211-21. doi:10.1021/bk-1994-0556.ch017.

[23] P. Hashemi, P.L. Walsh, T.S. Guillot, J. GrasNajjar, P. Takmakov, F.T. Crews, R.M. Wightman, Chronically implanted, nafion-coated $\mathrm{Ag} / \mathrm{AgCl}$ reference electrodes for neurochemical applications, ACS Chem. Neurosci. 2 (2011) 658-66. doi:10.1021/cn2000684.

[24] D. Chen, C. Wang, W. Chen, Y. Chen, J.X.J. Zhang, PVDF-Nafion nanomembranes coated microneedles for in vivo transcutaneous implantable glucose sensing, Biosens. Bioelectron. $\quad 74 \quad$ (2015) 1047-52. doi:10.1016/j.bios.2015.07.036.

[25] R.F. Vreeland, C.W. Atcherley, W.S. Russell, J.Y. Xie, D. Lu, N.D. Laude, F. Porreca, M.L. Heien, Biocompatible PEDOT:Nafion composite electrode coatings for selective detection of neurotransmitters in vivo, Anal. Chem. 87 (2015) 2600-2607. doi:10.1021/ac502165f.

[26] Z. Dai, H. Mohwald, Highly Stable and Biocompatible Nafion-Based Capsules with Controlled Permeability for Low-Molecular-Weight Species, Chem. Eur. J. 20 (2002) 4751-55. doi:10.1002/15213765(20021018)8:20.

[27] A. Kelarakis, E.P. Giannelis, Nafion as cosurfactant: Solubilization of nafion in water in the 
presence of pluronics, Langmuir. 27 (2011) 554-60. doi:10.1021/la103318u.

[28] A. Kelarakis, M.J. Krysmann, Trivial and NonTrivial Supramolecular Assemblies Based on Nafion, Colloids Interface Sci. Commun. 1 (2014) 31-34. doi:10.1016/j.colcom.2014.06.005

[29] A. Kelarakis, V. Havredaki, K. Viras, W. Mingvanish, F. Heatley, C. Booth, S.M. Mai, Aqueous solutions and gels of diblock copolymers of 1,2-butylene oxide and ethylene oxide studied by light scattering and rheology, J. Phys. Chem. B. 105 (2001) 7384-93. doi:10.1021/jp003364m.

[30] G. Sauerbrey, Verwendung von Schwingquarzen zur Wagungdiinner Schichten und zur Mikrowagung, Zeitschrift Fur Phys. 155 (1959) 206-22. doi:10.1007/BF01337937.

[31] M. Rodahl, F. Höök, A. Krozer, P. Brzezinski, B. Kasemo, Quartz crystal microbalance setup for frequency and $\mathrm{Q}$ - factor measurements in gaseous and liquid environments Quartz crystal microbalance setup for frequency and Q-factor measurements in gaseous and liquid environments, $66 \quad$ (1995) 3924-30. doi:10.1063/1.1145396.

[32] J. Hu, V. Baglio, V. Tricoli, A.S. Arico, V. Antonucci, PEO-PPO-PEO triblock copolymer/Nafion blend as membrane material for intermediate temperature DMFCs, J. Appl. Electrochem. 38 (2008) 543-50. doi:10.1007/s10800-007-9471-5.

[33] A. Kelarakis, J.J. Crassous, M. Ballauff, Z. Yang, C. Booth, Micellar spheres in high frequency oscillatory field, Langmuir. 22 (2006) 6814-17. doi:10.1021/la0607860.

[34] N. Goutev, Z. S. Nickolov, G. Georgiev, H. Matsuura, Hydration of a short chain poly(oxyethylene) (C1E2C1) studied by analysis of the $\mathrm{O}-\mathrm{H}$ Raman band, J. Chem. Soc., Faraday Trans. 93 (1997) 3167-71. doi:10.1039/A702629C
[35] A. Kelarakis, V. Havredaki, C. Booth, Aqueous gels of diblock oxyethylene-oxypropylene copolymers, Macromol. Chem. Phys. 204 (2003) 15-21.

[36] T.G. O'Lenick, X. Jiang, B. Zhao, Thermosensitive Aqueous Gels with Tunable Sol - Gel Transition Temperatures from Thermo- and $\mathrm{pH}$-Responsive Hydrophilic ABA Triblock Copolymer, Langmuir. 26 (2010) 8787-96. doi:10.1021/la9045308.

[37] A. Kelarakis, V. Castelletto, C. Chaibundit, J. Fundin, V. Havredaki, I.W. Hamley, C. Booth, Rheology and structures of aqueous gels of triblock(oxyethylene/oxybutylene/oxyethylene) copolymers with lengthy oxyethylene blocks, Langmuir. 17 (2001) 4232-39. doi:10.1021/la0101806.

[38] R. Chang, Y. Huang, G. Shan, Y. Bao, X. Yun, T. Dong, P. Pan, Alternating poly(lactic acid)/poly(ethylene-cobutylene) supramolecular multiblock copolymers with tunable shape memory and self-healing properties, Polym. Chem. 6 (2015) 5899-910. doi:10.1039/C5PY00742A.

[39] S.S. Kulthe, N.N. Inamdar, Y.M. Choudhari, S.M. Shirolikar, L.C. Borde, V.K. Mourya, Mixed micelle formation with hydrophobic and hydrophilic Pluronic block copolymers: Implications for controlled and targeted drug delivery, Colloids Surfaces B Biointerfaces. 88 (2011) 69196. doi:10.1016/j.colsurfb.2011.08.002

[40] G.M. Zentner, R. Rathi, C. Shih, J.C. Mcrea, M. Morgan, S. Weitman, Biodegradable block copolymers for delivery of proteins and water-insoluble drugs, J. Control. Release. 72 (2001) 203-15. doi:10.1016/S0168-3659(01)00276-0.

[41] V. Castelletto, I.W. Hamley, J.S. Pedersen, Small-Angle Neutron Scattering Study of the Structure of Superswollen Micelles Formed by a Highly Asymmetric Poly(oxybutylene)-Poly(oxyethylene) Diblock Copolymer in Aqueous Solution, Langmuir. 20 (2004) 2992-94. doi:10.1021/la036 